\title{
POLLINATION OF EUGLOSSINOPHYLIC EPIPHYTIC ORCHIDS IN AGROECOSYSTEMS AND FOREST FRAGMENTS IN SOUTHEAST MEXICO
}

\author{
ANNE DAMON ${ }^{1, *}$, FABIOLA HERNÁNDEZ-RAMÍREZ², LAURA RIGGI³, \\ RUDI VERSPOOR ${ }^{3}$, VINCENZO BERTOLINI ${ }^{1}$, MELISSA LENNARTZ- \\ WALKER ${ }^{3}$, ANDREW WILES 3 , and AILSA BURNS ${ }^{3}$ \\ ${ }^{1}$ El Colegio de la Frontera Sur, Apdo. Posta 36, Carretera Antiguo Aeropuerto km 2.5, Tapachula, Chiapas, C.P. 30700. \\ Tel.: +52 (962) 6289800 Ext. 5300; Fax: +52 (962) 6289806 \\ ${ }^{2}$ Faculty of Agricultural Sciences, Autonomous University of Chiapas (UNACH), Huehuetán, Chiapas \\ ${ }^{3}$ University of Edinburgh, Old College, South Bridge, Edinburgh, Scotland, UK. EH8 9YL \\ ${ }^{\star}$ Corresponding author: adamon@ecosur.mx
}

\section{ABSTRACT}

To determine the reproductive status of the native orchids of the biodiversity "hotspot", Biological Corridor Tacaná-Boquerón, in the region of Soconusco, southeast Mexico, which are suffering the effects of habitat degradation, unsustainable exploitation and potentially, climate change, we analysed the species richness, abundance, habitat and abiotic preferences, pollinaria transport and relation to orchid populations, of male Euglossine bees (Hymenoptera: Apidea: Euglossini) in agroecosystems and forest fragments within the region. Using volatile baits we trapped 2,480 bees, consisting of 14 species, during a total of 256 hours, of which 284 individuals (11.5\%) had pollinaria of 18 orchid species adhered to their bodies. Three species of Eufriesia (E. caerulescens, E. mexicana, E. rugosa) and one species of Euglossa (E. villosa) were recorded for the first time. We report Eulaema meriana as the pollinator of the recently rediscovered Plectrophora alata. We did not detect habitat preferences for the species of Euglossini captured, and they were frequent, or even more frequent, in intensive coffee plantations, as are many of the orchid species, which can be classified as a disturbed habitat. Bees tended to be more abundant with increasing light intensity and decreasing humidity at each site. There was little indication of pollinator specificity and the position of the pollinaria of each orchid species on the bodies of the bees was also variable. We did not recover any pollinaria from various euglossinophylic, epiphytic orchid species present in the region and three bee species showed signs of population decline. However, our results indicate that many species of orchids with this pollination syndrome are receiving pollination service within an increasingly fragmented and disturbed environment, suggesting that both the orchids and the bees are adapting to the changes.

Keywords: euglossine bees, orchid pollinaria, threatened species, Soconusco, biodiversity “hotspot”, Tacaná-Boquerón Biological Corridor

\section{Introduction}

Epiphytic orchids are mechanical parasites that live attached to the trunks, branches and twigs of bushes, lianas and trees and depend on suitable environmental conditions and the availability of host plants, pollinators and symbiotic fungi to complete their life cycle and maintain viable, reproductive populations. All these factors are under threat due to environmental degradation which, with time, may be exacerbated by climate change. Pollination, as one of these fundamental processes, is difficult to study in the case of epiphytes due to small, inaccessible and widely dispersed populations and infrequent, unpredictable visitation by pollinators (Pérez-Hernández et al. 2011). To corroborate pollinator decline it is virtually impossible to separate natural fluctuations, which would not affect population status in the long term, from true, threatening declines (Roubik 2001; Thomson 2001). It is also virtually impossible to determine the characteristics of a healthy viable population, in terms of how much space is required, how many populations, how many individuals per population and in total etc., and not only for the orchids themselves, but also for interacting pollinators and symbiotic organisms (Wilhere 2008).

The conservation of orchids depends upon the conservation of pollinators, symbiotic organisms (Bertolini et al. 2011) and host plants, some, or all of which may have an aggregated distribution (Jersáková and Malinova 2007), independently specific habitat requirements and be infrequent. Although there is little consensus on their effectiveness, and every organism responds uniquely, corridors that connect habitat fragments could also be very important for the maintenance of viable populations of many species (Gilbert-Norton et al. 2010). Despite their fame as fragile plants with very specific habitat and environmental requirements, many orchid species are surprisingly resilient and some terrestrial species have been found to be the first plants to colonize new habitats (Jersáková and Malinova 2007), to the extent that a few species have developed the characteristics of weeds (Ackerman 2007) and are sufficiently plastic to adapt to changing environmental conditions, pollinators and symbionts.

Despite extensive research into the subject, there are many unresolved questions about orchid pollination, the subject has been amply reviewed but a few details are worthy of emphasis. Many authors mention pollinator limitation as the most important cause of the low levels of seed set observed for many orchid species and particularly for epiphytic and rewardless species (e.g. Ackerman 1986; Johnson and Nilsson 1999). However, Thomson (2001) counteracted the assumption that all plants actually require and can sustain $100 \%$ pollination and subsequent fruit load and Pérez-Hernández et al. (2011) discussed 
the incongruence of using pollinator limitation as a justification for low fruit set in orchids and emphasized the importance of the compensatory vast numbers of seeds that are produced within each orchid seed capsule that results from every successful pollination event. The taxonomic diversity of the Orchidaceae is often attributed to adaptive radiation for specific pollinators driven by selection for outcrossing, although Tremblay and Ackerman (2007) suggest that there is very little evidence to support that hypothesis. The progeny that result from every successful pollination event should carry the genetic information that relates to the combination of characteristics that permitted that successful event. However, evidence suggests that, in the case of many orchids, particularly rewardless species, there are no consistent and identifiable attributes that determine whether a particular flower is pollinated or not, implying that successful pollination events occur due to chance or "luck" and are basically highly improbable (Pérez-Hernández et al. 2011). If that is indeed the case, there is little chance of selection to increase the likelihood of future successful pollination events, at best the genetic carry over permits future generations to remain within the realms of chance. Given that scenario, for many orchid species it is particularly difficult to determine whether the levels of pollination, fruit set and the other various components of sexual reproduction within an orchid population are adequate for long-term maintenance of viable populations.

This study is an integral part of the work being carried out by the project "Ecology and sustainable cultivation of orchids in Soconusco" (ECOSUR-Tapachula, Chiapas, Mexico) including the pollination of native euglossinophylic species which make up approximately $10 \%$ of orchid biodiversity of the region. We have developed an image data base of the pollinaria of the orchids of the region (Nieto and Damon 2008) for the identification of pollinaria found adhered to the bodies of insects and animals trapped.

Euglossine bees (Hymenoptera; Apidae; Euglossini) are frequent visitors that remain at flowers for minutes rather than seconds, and are fairly easy to trap, whereas this is certainly not the case for most other species that pollinate orchids. In a previous study carried out at low and middle altitudes in other parts of Soconusco region, Damon and Salas-Robledo (2007) reported the capture of 1480 male euglossine bees, of 11 species, of which $2.7 \%$ carried orchid pollinaria attached to their bodies.

The aim of this study was to determine the reproductive status of the native orchids of the biodiversity "hotspot", Biological Corridor Tacaná-Boquerón (Priority Terrestrial Region 135, Conabio), in the region of Soconusco, southeast Mexico, which are suffering the effects of habitat degradation, unsustainable exploitation and potentially, climate change (Damon 2011). To that effect, we present the results of 2 separate studies of euglossine bee pollination carried out by undergraduate students during the period 2007-2010.
In the largely descriptive first study (Section1), during one year we studied the diversity of male euglossine bee species present, pollinaria transport and habitat preferences in a wide range of sites within each of four orchid-rich transects within the Tacaná-Boquerón Biological Corridor. In the second, two month study (Section 2), we analyzed the abiotic and habitat preferences of male euglossine bees and hypothesized that they would prefer natural forest fragments to coffee agrosystems. We also hypothesized that these male, orchid-pollinating bees would prefer the higher humidity and lower temperature, light levels and wind speed found within each site, as compared to the "edges", for both natural forest fragments and coffee agrosystems.

\section{Materials and Methods}

\section{Study Area}

The Tacaná-Boquerón Biological Corridor is situated in the extreme southeast of the state of Chiapas, in Mexico, and is recognised as a biodiversity "hotspot" (CONABIO, RTP-135). The area covers $574 \mathrm{~km}^{2}$ between the coordinates: $14^{\circ} 53^{\prime} 24^{\prime \prime}-15^{\circ} 21^{\prime} 36^{\prime \prime} \mathrm{N}$ and $92^{\circ} 04^{\prime} 12^{\prime \prime}-$ $92^{\circ} 22^{\prime} 12^{\prime \prime} \mathrm{W}$ (Arriaga et al., 2000) and connects with the Mesoamerican Biological Corridor. Within the area, the Tacaná volcano is the highest point at $4100 \mathrm{~m}$.

At sea level and on the lower slopes of the Sierra Madre Mountains are the heavily fragmented remains of the only perennial tropical humid forest on the Pacific side of Mexico and Central America. The area also encompasses tropical montane moist forests (cloud forests), with varying vegetation composition including pine-oak and pine forests, now largely given over to coffee production and extensive cattle ranching. Higher altitudes consist of alpine and subalpine ecosystems.

Two independent studies were carried out, Section 1 working within four, $4 \mathrm{~km}$ transects during one year, and Section 2 working within four sites during a period of two months.

\section{Experimental sites}

\section{Section 1}

This study was set up to analyse in general the contribution of euglossine bees to the pollination of euglossinophylic orchids in the region with no specific hypothesis or repetitions, and no statistical analysis. We obtained data concerning the diversity of male euglossine bee species in the region, pollinaria transport, pollinaria position on the bodies of the bees, seasonal variation, synchrony with orchid flowering and habitat preferences.

Based on our experience in the region, we chose four orchid-rich, $4 \mathrm{~km}$ transects, representative of the extension 
of the Tacaná-Boquerón Biological Corridor and covering a wide range of habitats and environmental conditions. Guided by the results of test sampling runs, we excluded areas, mostly above $1600 \mathrm{~m}$, with low capture rates.

Weather permitting, monthly visits were carried out to each transect, with a different site chosen each time. There were a total of 49 visits carried out over a period of thirteen months. Data for the final two months were incomplete and for some parts of the analysis data are included for only eleven months (May 2009 - March 2010).

We chose transects centred on the following rural communities:

1. Fracción Montecristo, Municipality of Cacahoatán, altitude range $1401-1435 \mathrm{~m}$. The transect included traditional, shaded coffee plantations and intensified coffee plantations with Inga micheliana Harms (Fabaceae) as the shade tree.

2. Benito Juárez "El Plan”, Municipality of Cacahoatán, altitude range 1057-1464 m. Buffer zone of the Biosphere Reserve "Volcán Tacaná". The transect included traditional, shaded coffee plantations with a variety of native trees as shade, and intensified coffee plantations with I. micheliana.

3. Santa Rosalía, Municipality of Tapachula, altitude range $579-1410 \mathrm{~m}$. The transect included mainly traditional, shaded coffee plantations, with some highly intensified plantations semi-shaded with heavily pruned I. micheliana and/or timber trees. Some of the plantations have mature tree ferns.

4. Boquerón Buenavista, Municipality of Motozintla, altitude range $1018-2155 \mathrm{~m}$. The transect included patches of pine and oak-pine forest, traditional shaded coffee plantations and intensified plantations with I. micheliana and a few full sun coffee plantations.

\section{Section 2}

To analyse in detail the effects of habitat and abiotic environmental conditions upon euglossine bee abundance, species richness and pollination activity, during two months (June and July 2010) we used volatile baits to trap male euglossine bees in four sites, consisting of two coffee plantations and two forest fragments. Furthermore, each site was divided into two sections, "edge" and "centre", to indicate whether bees might be affected by the environmental changes caused by habitat fragmentation and deforestation. "Edges" were next to a path or clearing, and "centres" were areas up to $20 \mathrm{~m}$ within the coffee plantation or forest fragment where the vegetation was denser and abiotic conditions less extreme and more stable.

The coffee plantations were: Perú-París (PP), Municipality of Tapachula, at $941 \mathrm{~m}$, and Llano Grande (LG), Municipality of Motozintla, at $1121 \mathrm{~m}$.

The forest fragments were in Belisario Domínguez (BD), Municipality of Motozintla, at $506 \mathrm{~m}$ and Peloponeso (P), Municipality of Tapachula, at $1297 \mathrm{~m}$.

\section{Habitat preference}

Differences in bee abundance between sites and habitats (forest fragments and coffee plantations) were compared using a parametric ANOVA test. "Edge" and "centre" effect on bee abundance was estimated using a t-test.

\section{Abiotic data}

Using a climate metre (LM-8000) and compass, data were taken every $30 \mathrm{~min}$, of temperature $\left({ }^{\circ} \mathrm{C}\right)$, humidity (RH\%), light level (Lux), wind speed and wind direction $(\mathrm{km} / \mathrm{hr})$. The timing of every bee capture was recorded and later integrated with the abiotic data.

The environmental variables of temperature, relative humidity and light intensity, were averaged over the three baits set up for each site, "edge" and "centre". Average values over 30 minutes were analyzed using linear regressions and correlation analysis. To estimate the effect of these variables within each sampling site and over the four sites we conducted analyses of variance (ANOVA) for the total number of bees collected, for the most abundant genera (Euglossa) and for each of the two most abundant species (Euglossa tridentata and E. viridissima). For the analysis we summed the total number of bees collected in each 30 minutes time period. Bee abundances were transformed using $\log (\mathrm{x}+1)$ to homogenise variances.

\section{Species richness and abundance}

Diversity indexes were calculated using EstimateS software (Version 8.2, R. K. Colwell, http://purl.oclc .org/estimates); $\alpha$-diversity indices of Simpson (1/D, reciprocal value listed) and Shannon $(\mathrm{H})$ were calculated. Although diversity indices have no intrinsic biological meaning, they are useful for comparing the combination of the number of species (richness) and their relative abundance (evenness) among communities.

To compare species abundance between the four sites, an evenness measure (E1/D) was calculated by dividing the Simpson index by the number of species in each sample.

In all cases unidentified species were not included in the analysis.

\section{Volatile Baits (Applicable to Sections 1 and 2)}

As a result of previous research into the fragrance preferences of euglossine bees in the Soconusco region (Damon and Salas-Robledo 2007, and unpublished data) and the analysis of the composition of a wide range of orchid fragrances (Del Mazo-Cancino and Damon 2007; Velásquez Velasco 2007), we selected the following volatile substances as baits in this study: For Section 1 of the study: 1,8-cineole, eugenol, methyl salicylate, methyl cinnemate, $\mathrm{p}$-cymene, $\mathrm{p}$-dimethoxybenzene and vanilla, and for Section 2: cineole, eugenol and methyl cinnamate. We 
soaked cotton dental rolls with the individual substances which were hung $5 \mathrm{~m}$ apart, at head height, from twigs and branches, using thin, grey, plastic-covered wire. The baits were set up at $09.00 \mathrm{hrs}$ and removed at $13.00 \mathrm{hrs}$, after which time activity declined and the rain began (June to November).

The baits were checked in sequence approximately every $30 \mathrm{~min}$. For both sections, bees carrying pollinaria were placed into killing jars with Vaportape II $^{\circ}$ (Bioquip), labelled with details of bee species, date, site, volatile substance and time of capture, and taken to the Scanning Electron Microscope (SEM) Laboratory in ECOSUR, Tapachula for identification of the pollinaria. To prevent recapture, bees without pollinaria were stored in large jars with one extreme sealed with mosquito netting, in the shade, to avoid overheating and suffocation, and released at the end of the sampling period. The bees without pollinaria were only identified and included in the analysis in Section 2 of the study.

\section{Identification of orchid pollinaria}

(Applicable to Sections 1 and 2)

In the SEM Laboratory of ECOSUR, Tapachula, first, a photograph was taken of each bee with the pollinaria adhered to the body and then the pollinaria were removed. The pollinaria were mounted ready for observation using the SEM Topcon SM 510 as described in Nieto and Damon (2008). Photographs of the pollinaria were taken under low vacuum and compared with the image data base "Orchid Pollinaria of Southeast Mexico" (Nieto and Damon 2008). Photographs of the pollinaria obtained in Section 1 of the study are included in Hernandez-Ramirez (2010).

\section{Results and Discussion}

\section{Total euglossine bees captured, capture rate, pollinaria transport}

In Section 1 of the study (Hernández-Ramírez 2010) we carried out 49 visits during 13 months, giving a total of 196 hours of trapping, in which 1229 male euglossine bees were caught, consisting of 9 species from 3 genera. Of those, 221 individuals (18\%) had pollinaria of 15 orchid species adhered to their bodies.

During the two month period of Section 2 of the study, with a total of 60 hours, 1251 male euglossine bees were trapped, consisting of 14 species from 4 genera. Of those, 63 individuals $(5 \%)$ had pollinaria from 8 species of orchids adhered to their bodies.

Combining the two studies, three species of Eufriesia (E. caerulescens, E. mexicana, and E. rugosa) and one species of Euglossa (E. villosa) were recorded for the first time in the region, all of which, except for one specimen of E. mexicana, were not carrying orchid pollinaria when trapped. We report Eulaema meriana as the pollinator of the recently rediscovered Plectrophora alata.

Comparing our data with the results reported by Damon and Salas-Roblero (2007), in which 1480 individual bees of 11 species were captured in two sites during a period of one year, totalling 120 hours (approximately 12 bees per hour), in Section 1 where 49 different sites were visited during a period of one year, the capture rate was half that rate, at 6 per hour, and in the four sites of Section 2, much higher, at 20 per hour, bearing in mind that in the case of Section 2, bees were trapped only during June and July. The percentage of bees carrying pollinaria was notably higher in Section 1 , at $18 \%$, and slightly higher in Section 2, at 5\%, compared with $2.7 \%$ obtained by Damon and Salas-Roblero (2007). These results suggest that euglossinophilic orchids continue to receive adequate pollination service in the region, despite increasing deforestation and other types of habitat fragmentation and deterioration, and we might even propose that many species of euglossine bees are adapting successfully to these changes. However, one species, Euglossa mixta, which appeared at the baits in 2007, was not observed in either Section 1 or 2, and the two Eulaema species (E. cingulata and E. meriana) were less frequent, which may indicate decline of these species in the area and be a cause for concern.

\section{Position of pollinaria transported by eugossine bees}

We noted the position of the pollinaria on the bodies of the bees and contrary to current opinion, positioning was not as specific as expected; in the case of Lycaste sp., Mormodes lineata, Notylia barkeri, Stanhopea saccata and Trichocentrum candidum the position was particularly variable; pollinaria of these orchids were also carried by a variety of species of bees. This might imply that the pollination service was ineffective and that the pollinaria might be less likely to reach its destination or maybe that precision of placement is not specific and not as important for effective pollination, as previously thought? It is interesting to note that all these species, except for Lycaste sp., are amongst the most abundant species in the region and that could be due to a certain degree of flexibility in terms of pollinators and pollinaria placement.

\section{Seasonal variation}

The number of bees captured and the percentage that was carrying orchid pollinaria at the moment of capture was highly variable between these two studies and the Damon and Roblero (2007) study with considerable seasonal variation. As shown in Fig. 1, in Section 1 of this study (Hernández-Ramírez 2010) by far the most bees were trapped in June, coinciding with the highest percentage of bees carrying pollinaria. Captures were also higher in July, August, September which are all rainy season months, and December in the dry season. However, 


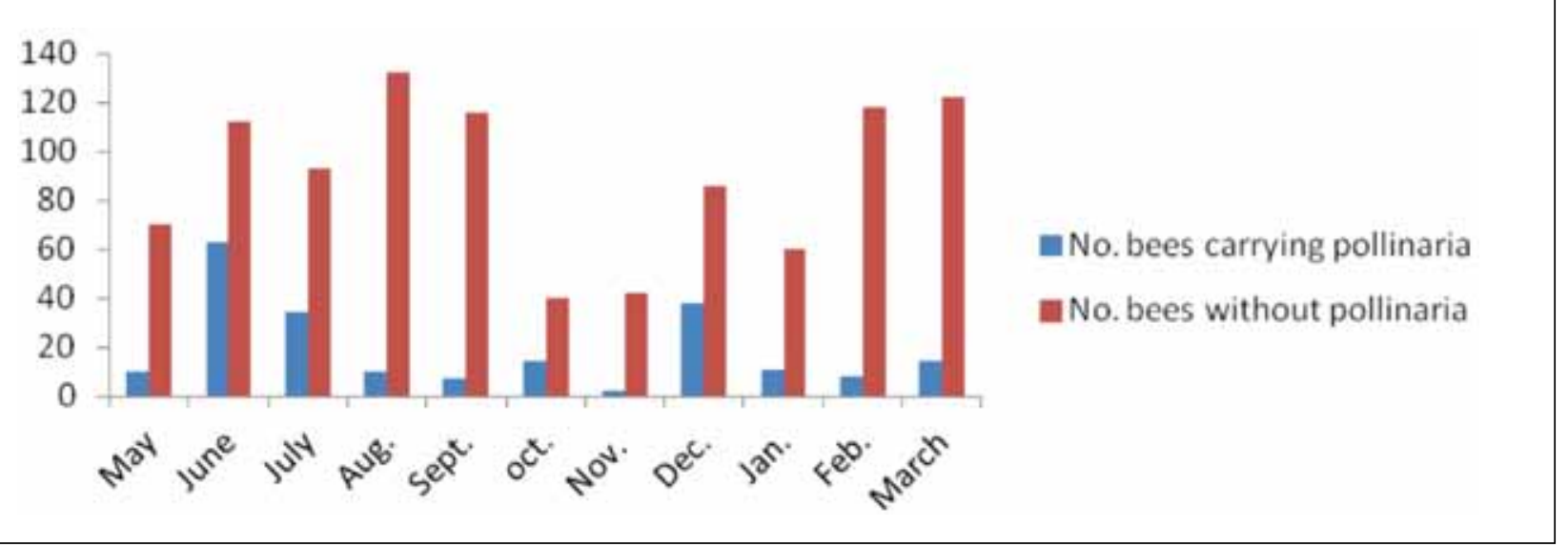

Fig. 1 Section 1. Number of individual euglossine bees, with and without pollinaria attached to their bodies, captured between May 2009 and March 2010, in four, 4 km transects within the Tacaná-Boquerón Biological Corridor.

Damon and Roblero (2007) reported similar numbers of most of the euglossine bee species throughout the year, except for a peak in numbers of E. viridissima observed in June in the site at $900 \mathrm{~m}$, and a peak in numbers of $E$. tridentata in the coastal site at $80 \mathrm{~m}$ in the early dry season months (October to February), with much lower numbers from April (still dry, the rain season begins in May or June) until the end of the rainy season (September).

Overall the variation of numbers of bees trapped and the absolute numbers of pollinaria and percentage of bees

Table 1 Epiphytic, euglossinophylic orchids of the Biological Corridor Tacaná-Boquerón: Timing of flowering, and transport of pollinaria by euglossine bees.

Data are included for Section 1 and Section 2 of this study, as well as data from Damon and Salas Roblero (2007) and other observations during the 10-year period of studying orchids in the region. Three types of pollinaria were identified to genus level because of lack of images of other candidate species. Various pollinaria could not be identified as they did not coincide with any of the pollinaria so far characterized.

\begin{tabular}{|c|c|c|c|c|c|c|c|c|c|c|c|c|}
\hline \multirow{3}{*}{ Orchid species } & \multicolumn{12}{|c|}{ Month } \\
\hline & \multicolumn{12}{|c|}{$\begin{array}{l}\text { Observed flowering in the region }(\mathrm{X}) \\
\text { Period of capture of euglossine bees carrying pollinaria (shaded) }\end{array}$} \\
\hline & III & IV & $\mathrm{V}$ & $\mathrm{VI}$ & VII & VIII & IX & $\mathrm{x}$ & $\mathrm{XI}$ & XII & I & II \\
\hline Catasetum integerrimum Hook & $\mathrm{x}$ & & $\mathrm{x}$ & $\mathrm{x}$ & $\mathrm{x}$ & $\mathrm{x}$ & $\mathrm{x}$ & & & & $\mathrm{x}$ & \\
\hline Cycnoches egertonianum Bateman & & & & $\mathrm{x}$ & & $\mathrm{x}$ & & & & & & \\
\hline Cycnoches ventricosum Bateman & & & & $x$ & $\mathrm{x}$ & $\mathrm{x}$ & & & & & & \\
\hline Gongora cassidea Rchb.f. & & & $\mathrm{x}$ & & $\mathrm{x}$ & & & & & & & $\mathrm{x}$ \\
\hline \multicolumn{13}{|l|}{ Gongora tridentata Whitten } \\
\hline Guarianthe skinneri (Bateman) Dressler and W.E. Higgins & & & & & & & & & & $x$ & $x$ & \\
\hline Kefersteinia lactea (Rchb.f.) B.D. Jacks. & & & & $x$ & $\mathrm{x}$ & $\mathrm{x}$ & & & & & & \\
\hline Lockhartia verrucosa Lindl. ex Rchb.f. & $x$ & & & & & & & & $x$ & & & \\
\hline Lycaste cruenta Lindley & $x$ & $\mathrm{x}$ & $x$ & $x$ & $\mathrm{x}$ & & & & & & & \\
\hline Lycaste sp. (possibly L. aromatica (Graham ex Hook.) Lindl.) & & $\mathrm{x}$ & & & & & & & & & & \\
\hline Meiracyllium trinasutum Reichb.f. & $\mathrm{x}$ & $\mathrm{x}$ & $\mathrm{x}$ & & & & & & & $\mathrm{x}$ & & \\
\hline Mormodes lineata Bateman ex Lindley & $\mathrm{x}$ & $\mathrm{x}$ & & & & & & & $x$ & $\mathrm{x}$ & $x$ & $\mathrm{x}$ \\
\hline \multicolumn{13}{|l|}{ Mormodes sp. (possibly M. aromatica Lindl. ) } \\
\hline Notylia barkeri Bateman ex Lindley & $\mathrm{x}$ & & $x$ & $\mathrm{x}$ & & $\mathrm{x}$ & & & $\mathrm{x}$ & $\mathrm{x}$ & $\mathrm{x}$ & $\mathrm{x}$ \\
\hline Plectrophora alata (Rolfe) Garay & $x$ & & & & & & & & & $\mathrm{x}$ & & $\mathrm{x}$ \\
\hline Sobralia decora Bateman & & & & & & & & & $x$ & $\mathrm{x}$ & $\mathrm{x}$ & $\mathrm{x}$ \\
\hline Sobralia macrantha Lindl. & & $\mathrm{x}$ & $\mathrm{x}$ & $\mathrm{x}$ & & & & & & $\mathrm{x}$ & & \\
\hline Sobralia sp. (possibly S. macdougallii Soto Arenas, Pérez-García and Salazar) & $\mathrm{x}$ & & & & & & & & & $\mathrm{x}$ & & \\
\hline Stanhopea saccata Bateman & & & & $\mathrm{x}$ & $\mathrm{x}$ & & & & & & & \\
\hline Trichocentrum candidum Lindley & $x$ & & & $\mathrm{x}$ & $\mathrm{x}$ & & $x$ & $\mathrm{X}$ & $x$ & $x$ & $x$ & $x$ \\
\hline Trichopilia tortilis Lindley & $\mathrm{x}$ & $\mathrm{x}$ & $\mathrm{x}$ & $\mathrm{x}$ & & $\mathrm{x}$ & & & & & & \\
\hline
\end{tabular}


carrying pollinaria did not follow any particular pattern, there are many factors, such as rainfall, availability of other resources, human intervention, bee life cycle, predation and disease etc. that contribute to such fluctuations.

Table 1 shows that there is some overlap between the timing of flowering of each euglossinophilic orchid species in Soconusco region and the timing of the capture of euglossine bees carrying pollinaria. However, many pollinaria-carrying bees were captured outside the observed flowering times, suggesting that those pollinaria might be lost to the population for reproduction purposes, or that there are a few populations of orchids with unusual flowering times. Of the 21 euglossinophylic species that we have observed in the region, for 3 species we have never captured bees carrying their pollinaria, including the charismatic and over exploited G. skinneri, now virtually extinct in the wild but still abundant and often pollinated in home gardens. Various other euglossinophyllic species have been recorded historically in the region but may now be extinct (Damon 2011).

\section{Abiotic effects}

In Section 2 of the study we compared the variation in abundance of orchid bees with abiotic factors in remnants of tropical forest (forest fragments) and in coffee plantations, per genus (Fig. 2) and per species of Euglossa (Fig. 3). Observed trends in abundance were driven by data collected for the dominant species, E. tridentata and the low sample sizes of various species prevented comparisons between them.

Contrary to our hypothesis, in general, bees tended to be more, not less, abundant with increasing light intensity and decreasing humidity at each site. Analysis of variance (ANOVA) showed a significant effect of light intensity and relative humidity on the distribution of abundance of male euglossine bees within the sites, (humidity: $\mathrm{F}_{1,234}=58.38, \mathrm{P}<<0.001$; and light intensity: $\left.\mathrm{F}_{1,234}=4.27, \mathrm{P}<0.05, \mathrm{R}-\mathrm{Sq}(\mathrm{adj})=35.78 \%\right)$. Temperature was not significant overall although numerical increase in bee abundance at higher temperatures was observed in various cases.

T-tests demonstrated significant differences in environmental conditions between "edge" and "centre" positions within each sampling site. In general, temperature and light intensity were highest and humidity lowest at the "edge" with greater variation in all parameters at the "edge". However, despite the different abiotic conditions, and the abiotic preferences mentioned previously, analysis did not confirm an interaction between bee abundance and the "edge" or "centre" of each site $\left(\mathrm{F}_{1,234}=3.30\right.$; $\mathrm{P}=0.071$ ), suggesting that small scale abiotic variation is not necessarily a deterrent to euglossine bee movements. Nevertheless, "edges" in general had slightly more bees than in the centre, although this may have been due to other unmeasured variables influencing odour dispersal, sampling ease, and visibility.

\section{Euglossine abundance}

Changes in abundance with variations in environmental parameters was not surprising as several resources necessary to male euglossines, such as food and the production of fragrances, are sensitive to abiotic changes. Although our results suggest that bees respond to ephemeral local conditions, such as humidity and light intensity, whether or not these variables are the factors that determine distribution, habitat preferences and seasonal fluctuations is a subject for further study.

In Section 2, the most common species was Euglossa tridentata ( $45.63 \%$ of all specimens), followed by $E$. viridissima $(18.86 \%)$. The four sites varied significantly in the total abundance of bees captured $\left(\mathrm{F}_{3,234}=49.61 ; \mathrm{P}<<\right.$ $0.005 ; \mathrm{R}-\mathrm{Sq}=38.39 \%$ ), with the two coffee plantation sites (LG, PP) having the highest abundance of bees. ANOVA indicated significant differences in the abundance of the dominant species, E. tridentata $\left(\mathrm{F}_{3,234}=59.47 ; \mathrm{P}<<0.001\right)$.

\section{Species richness}

To compare bee diversity in the four sites, we plotted the relative number of individuals against their rank to obtain an estimate of species richness and evenness. Rank-abundance curves for PP, and PEL sites were topo-
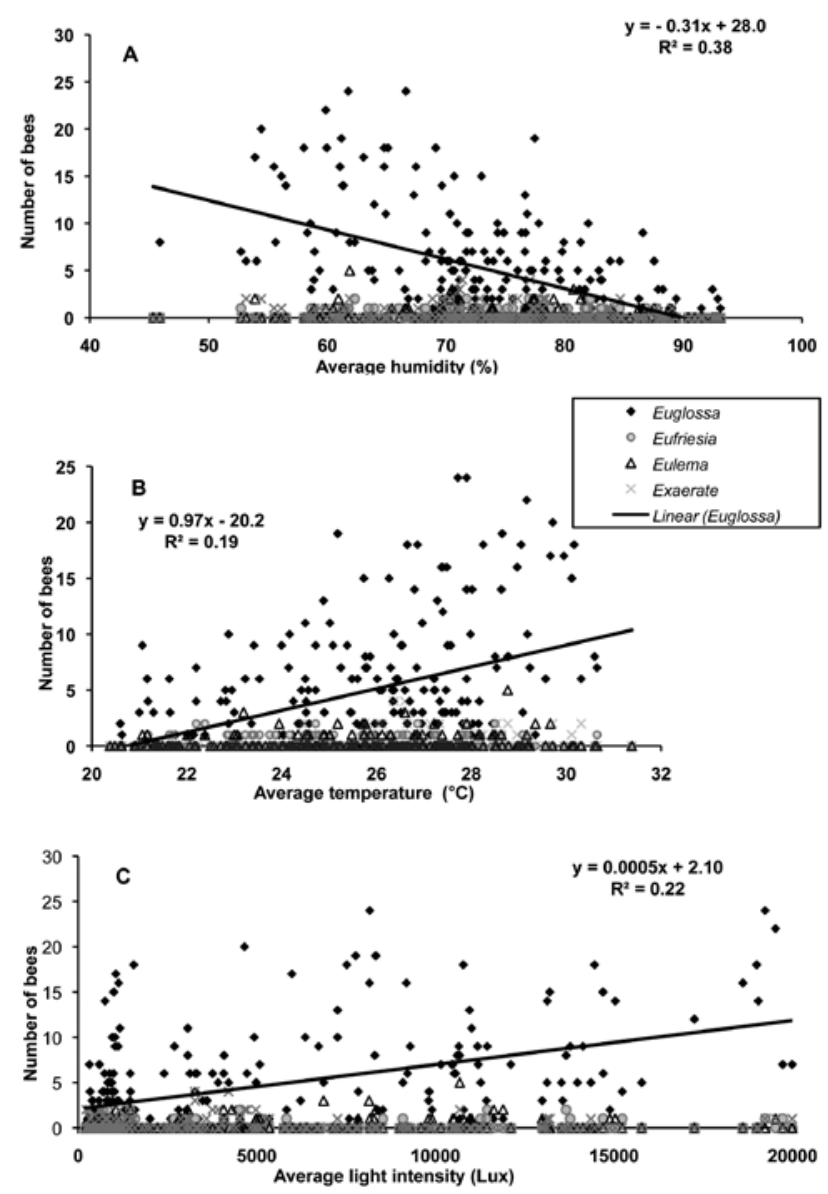

Fig. 2 Section 2. The relation between the abiotic factors and the abundance of bees of the tribe Euglossini, per genus. A. Relative Humidity (\%), B. Temperature $\left({ }^{\circ} \mathrm{C}\right)$, C. Light intensity (Lux). 


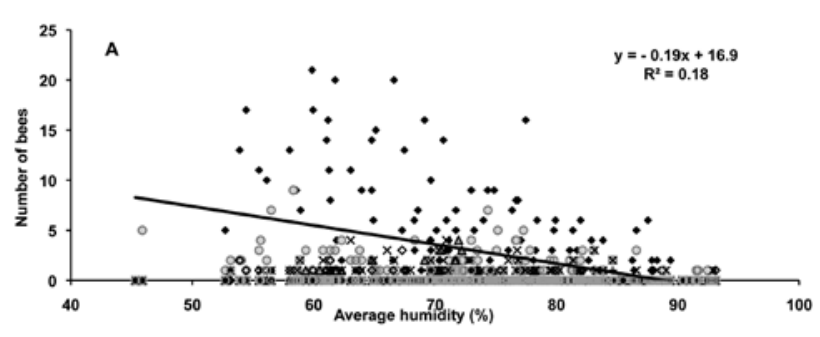

Table 2 Section 2. Diversity indexes for euglossine bees at four sites in the Tacaná-Boquerón Biological Corridor, BD (Belisario Domínguez, forest fragment), PEL (Peloponeso, forest fragment), PP (Peru Paris, coffee plantation), LG (Llano Grande coffee plantation).

\begin{tabular}{|l|c|c|c|c|c|}
\hline & BD & PEL & PP & LG & Total \\
\hline Total & 196 & 157 & 666 & 344 & 1364 \\
\hline Bee species & 11 & 10 & 11 & 11 & 14 \\
\hline Simpson's (1/D) & $\begin{array}{c}3.35 \\
(+/-1.09)\end{array}$ & $\begin{array}{c}3.93 \\
(+/-1.5)\end{array}$ & $\begin{array}{c}3.42 \\
(+/-1.01)\end{array}$ & 3.21 & - \\
\hline Shannon-Wiener (H) & $\begin{array}{c}1.56 \\
(+/-0.27)\end{array}$ & $\begin{array}{c}1.7 \\
(+/-0.28)\end{array}$ & $\begin{array}{c}1.65 \\
(+/-0.18)\end{array}$ & 1.65 & - \\
\hline Evenness (E1/D) & 0.305 & 0.393 & 0.311 & 0.292 & - \\
\hline
\end{tabular}

\section{Habitat effects}

Our results revealed general activity patterns and some aspects of the response of euglossine bees to habitat quality. Combining Sections 1 and 2, habitat, as we defined it (various types of coffee agroecosystems, forest fragments, disturbed versus natural habitats), did not appear to be a major determining factor of euglossine bee abundance and diversity. Volatile baits and natural orchid flower volatiles disperse in air and the nature of the vegetation may intervene significantly in that process and could have influences our results. However, in Section 2 of the study, differenced in bee abundance between coffee plantations and forest fragments were statistically significant $\left(\mathrm{F}_{1,234}=\right.$ $82.17, \mathrm{P}<<0.00, \mathrm{R}-\mathrm{Sq}(\mathrm{adj})=25.65 \%$ ), with most bees being caught in coffee plantations. That difference, however, was probably due to the fact that one of the coffee plantation sites (PP), had an unusually high bee abundance ( $\mathrm{N}=669,53.5 \%$ of bees caught in all four sites). Although we cannot conclude a significant habitat effect, our results show that euglossine bees can be abundant in intensively managed coffee plantations.

With more research we should find certain component factors that determine whether a euglossine species is present and can flourish within a site, such as a key food source, or nesting substrate, etc. Female euglossines do not usually visit scented baits, so in all of these studies only the males were monitored, with no information on the response of females to the variables tested.

In the case of orchids, habitat certainly is a defining factor for many species and Trichocentrum candidum was the only species that was found in all the habitats visited in Section 1 of this study, from natural, undisturbed vegetation to full sun coffee plantations. Our research in the region has revealed that the majority of orchids are restricted to protected areas and forest fragments, with only approximately $10 \%$ behaving as flexible, "weedy", opportunistic type species. However, within that scenario, many of the euglossinophylic, epiphytic orchid species are presently more frequent in coffee plantations rather than in forest fragments or undisturbed forest (Damon 2011).

Although some evidence (e.g., Brosi 2009) suggests that fragment size affects euglossine bee abundance, with more bees present in larger fragments due to greater availability 
of resources, the literature mostly supports evidence that euglossine bees forage in disturbed habitats. Tonhasca et al. (2002) and Rasmussen et al. (2009) did not find significant differences in euglossine communities between conserved and fragmented/disturbed habitats. Cane (2001) found a great diversity of euglossine bee species in highly fragmented and disturbed sites and Otero and Sandino (2003) reported higher diversity in secondary forest and agroecosystems. In this study, species composition was fairly similar between sites, but bees were clearly more abundant in one of the transects in Section 1 of the study, with the most intensive, semi-shaded coffee plantations.

A high proportion of accessible land between 500 and $1600 \mathrm{~m}$ in the Tacana-Boquerón Biological Corridor is given over to coffee production and our results indicate that all types of coffee plantations, from traditional, rustic systems with original forest trees as shade to full sun coffee, may be suitable habitat for most euglossine bee species, and may serve as suitable conservation areas for euglossine bees. In Section 2 of the study the total number of bees was highest in the coffee plantations, with the most disturbed plantation (PP), having a significantly higher abundance and a comparable richness of euglossine bee species.

\section{Euglossine bees and euglossinophylic orchids in Soconusco, southeast Mexico}

In the literature, we understand that approximately $10 \%$ of American orchid species are pollinated by euglossine bees, and from our list of 293 orchids registered for the Tacaná-Boquerón Biological Corridor we might expect approximately 29 euglossinophilic species. However, we found pollinaria of only 18 species of orchids, and mention another 3 that we have observed in the region, and presume or know to be euglossinophilic, but for which we have no evidence of pollinaria transport. This may indicate crisis point for those species, either because of insufficient pollination service due to increasing scarcity or extinction of specific euglossine pollinators, or because of declining population levels of orchids due to habitat loss. However, it is also possible that some of these supposedly euglossinophilic orchids have always been, or have more recently adapted to other, non-euglossine pollinators.

Orchids are usually considered to be specific to one species of pollinator or at most two or three. However, in this study, only three of the euglossinophylic, epiphytic orchid species were found to have their pollinaria transported by only one species of euglossine bee, these being Catasetum integerrimum, Cycnoches ventricosum, and Plectrophora alata, of which C. integerrimum is a very frequent, "weedy species", C. ventricosum, is a threatened species and P. alata is rare. Pollinaria of Trichopilia tortilis and Lycaste cruenta, less frequent but not threatened species, and of Kefersteinia tinschertiana, a threatened species, were found on two euglossine bee species. Various species are clearly generalist. Notylia barkeri and Mormodes lineata are frequent species found in disturbed habitats and their pollinaria have been found on five species of euglossine bees in the region, whereas Stanhopea saccata and Trichocentrum candidum also frequent in disturbed habitats and have their pollinaria transported by 6 species of euglossine bees. Similarly, Euglossa tridentata has been found with pollinaria of 10 orchid species, E. atroveneta with 9 and E. viridissima with 8 .

Some of the orchid species in this study flower variably and intermittently throughout the year, for example $N$. barkeri and T. candidum, whereas others, such as C. ventricosum, K. tinschertiana, and S. saccata have more restricted and specific flowering times. Flowering times of these species may be stimulated by discrete abiotic factors such as changes in temperature or rainfall, which have become increasingly erratic in the region as a result of deforestation and possible climate change.

The newly registered species of euglossine bees were found in limited areas that probably indicate geographic limits, not necessarily habitat preferences. E. caerulescens and E. villlosa were found in the northern extreme of the region and E. rugosa at the southern extreme. We have no data concerning the orchid species frequented by these bees.

According to Winkler et al. (2009), for studying the population dynamics of epiphytic orchid species, both local (within host tree) and regional (between trees) processes and the development of metapopulation models are important. There is competition for seeds to colonize new but potentially inadequate sites and to continue populating the safe area surrounding the mother plant where mycorrhizal fungi are presumably available to facilitate the germination of the seeds. Most recruitment occurs within the vicinity of the mother plant and the long distances flown by euglossine bees may, therefore be particularly important for maintaining genetic diversity and promoting interchange at a metapopulation level. Although the low levels and unpredictability of pollination would serve to minimize that effect, they are compensated by the fact that each successful pollination event produces thousands to millions of seeds (Damon and Valle-Mora 2008; Hernández-Pérez et al. 2011).

In general, it appears that orchid pollinator availability is very variable in Soconusco; this question must be taken into account when planning for sustainable orchid production and conservation in the region. While this study shows that euglossine bees are present and available as pollinators, and adaptable to forest fragments and coffee agroecosystems, if orchid numbers continue to decline, attention of available insects may be diverted towards new and richer sources of nectar, resins and fragrances, and in the long term this particular mutualism may reach an evolutionary dead-end and disappear.

\section{Volatile baits}

As usual, cineole and P-dimethoate were the substances that attracted most bees, and eugenol and vanillin also 
attracted substantial numbers of bees. Unusual or notable results were that a methyl salicylate bait attracted an individual of E. meriana, methyl cinnamate baits attracted various individuals of Euglossa crininota and for the first time P-cymene was used and attracted a single individual of E. tridentata. The fragrance of the bait where a bee is trapped appears to have no relation to the fragrance of the orchid whose pollinaria the bee is carrying. Euglossine bees do not depend on orchids and their objective is to accumulate quantity and quality of fragrance elements. However, the orchid does depend on the bee for pollination and requires that the pollinaria-carrying bee visits at least a second flower, and hopefully a series of flowers of the same species, and for that, euglossine bees are mostly guided by fragrance. Orchid fragrances can be very complex and to date no research has been carried out to determine the active substances in the fragrances of specific species.

\section{Conclusions}

Our results showed that euglossine bee abundance was significantly related to relative humidity and light intensity, marginally related to habitat type and not related to position within each site ("edge" or "centre"). Most bee species were frequent or even more frequent in intensive coffee plantations, which can be classified as a disturbed habitat.

The results contradict some of the paradigms related to orchids, for example, for the 18 species of euglossinophylic, epiphytic species for which we recovered pollinaria, there was little indication of pollinator specificity and the position of the pollinaria of each orchid species on the bodies of the bees was also variable.

We did not recover any pollinaria from the euglossinophylic, epiphytic orchid species of the genera Dichaea, or of Acineta barkeri, Clowesia russeliana, Gongora tridentata, Guarianthe skinneri, Lockhartia verrucosa, various species of Stanhopea, Sobralia, and Vanilla sp. all registered in the region. We have trapped bees in all months of the year and in a wide range of locations throughout the region, suggesting that there is indeed a problem with the pollination of these species. Similarly, the bee species Euglossa mixta, Eulaema cingulata, and Eulaema meriana may be in decline in the region and be a cause for concern.

In general our results indicate that 18 species of euglossinophyllic epiphytic orchids are receiving pollination service within an increasingly fragmented and disturbed environment, including intensively managed coffee agroecosystems. It appears that both orchids and bees are adapting to the changes, becoming more generalist, sharing resources and we might see convergent evolution in action in the long-term. The results also indicate that a similar number of orchid species supposedly with this pollinator syndrome are possibly now not receiving pollination services (or at least not by euglossine bees) and may suffer declines in their populations in the medium and long term, or a change of pollinator.

\section{Acknowledgements}

We are grateful to Ma. Guadelupe Nieto for processing the orchid pollinaria in this study. The research was funded by FONDOS MIXTOS-CHIAPAS. CONACyT. CHIS-2006-C06-45802. 2007-2010. (Project: "Diversidad y conservación de las orquídeas del corredor biológico Tacaná-Boquerón"), and included a grant for the second author. We would also like to thank the University of Edinburgh for a number of expedition grants, The Carnegie Fund, the Scottish Royal Geographic Society, the John Rae Trust and the Explorers Fund for financial and logistical support.

\section{REFERENCES}

Ackerman JD (2007) Invasive orchids: Weeds we love to hate? Lankesteriana 7: 19-21.

Ackerman JD (1986) Mechanisms and evolution of food deceptive pollination systems in orchids. Lindleyana 1: 108-113.

Arriaga L, Espinoza JM, Aguilar C, Martínez E, Gómez L, Loa E (2000) Regiones terrestres prioritarias de México. Comisión Nacional para el Conocimiento y uso de la Biodiversidad, México.

Bertolini V, Damon A, Velásquez ANR (2011) Symbiotic germination of three species of epiphytic orchids susceptible to genetic erosion, from Soconusco (Chiapas, Mexico). Eur J Env Sci 2: 60-68.

Brosi BJ (2009) The effects of forest fragmentation on euglossine bee communities (Hymenoptera: Apidae: Euglossini). Biol Cons 142: 414-423.

Cane JH (2001) Habitat fragmentation and native bees: a premature verdict? Cons Ecol 5: 3.

Damon A (2011) Diversidad y conservación de las orquídeas del corredor biológico Tacaná-Boquerón Final report. Fondos Mixtos-Chiapas: CHIS-2006-C06-45802. Conacyt, Mexico.

Damon A, Valle-Mora J (2008) Retrospective spatial analysis of the pollination of two miniature epiphytic orchids with different pollination strategies in a coffee plantation in Soconusco, Chiapas, Mexico. Bot J Linn Soc 158: 448-459.

Damon A, Salas-Roblero P (2007) A survey of pollination in remnant orchid populations in Soconusco, Chiapas, Mexico. Trop Ecol 48: 1-14.

Del Mazo Cancino A, Damon A (2007) Fragrance analysis of euglossine bee pollinated orchids from Soconusco, south-east Mexico. Pl Sp Biol 22: 129-134.

Gilbert-Norton L, Wilson R, Stevens JR, Beard KH (2010) A metaanalytic review of corridor effectiveness. Cons Biol 24: 660-668.

Hernández-Ramírez F (2010) Identificación de polinias e insectos polinizadores de orquídeas en el corredor biológico BoquerónTacaná, Chiapas. B.Sc. thesis. Faculty of Agricultural Sciences, UNACH, Chiapas, Mexico.

Jersáková J, Malinova T (2007) Spatial aspects of seed dispersal and seedling recruitment in orchids. New Phytol 176: 237-241.

Johnson SD, Nilsson LA (1999) Pollen carryover, geitonogamy, and the evolution of deceptive pollination systems in orchids. Ecology 80: 2607-2619. 
Nieto G, Damon A (2008) Guide to the morphology of the pollinia and pollinaria of orchids from southeast Mexico. Selbyana 29: 20-68. Special edition.

Otero JT, Sandino JC (2003) Capture rates of male euglossine bees across a human intervention gradient, Choco region, Colombia. Biotropica 35: 520-529.

Pérez-Hernández H, Damon A, Valle Mora J, Sánchez-Guillen D (2011) Orchid pollination: specialization in luck? Bot J Linn Soc 158: 448-459.

Rasmussen C (2009) Diversity and abundance of orchid bees (Hymenoptera: Apidae, Euglossini) in a tropical rainforest Succession. Neotrop Entomol 38: 66-73.

Roubik DW (2001) Ups and downs in pollinator populations: When is there a decline? Cons Ecol 5: 2.

Roubik DW, Hanson PE (2004) Orchid bees of tropical America: Biology and field guide. Instituto Nacional de Biodiversidad (INBio), Heredia, Costa Rica.
Tonhasca A, Blackmer JL, Albuquerque GS (2002) Within-habitat heterogeneity of euglossine bee populations: a re-evaluation of the evidence. J. Trop Ecol 18: 929-933.

Thomson JD (2001) Using pollination deficits to infer pollinator declines: Can theory guide us? Conservation Ecology 1: 6 [online] URL: http://www.consecol.org/vol5/iss1/art1/.

Tremblay RT, Ackerman JD (2007) Evolution in small populations: Evidence from the literature and experimental results. Lankesteriana 7: 223-228.

Velásquez Velasco PC (2007) Análisis químico de las fragancias de orquídeas epífitas del Soconusco con diferentes síndromes BSc. Thesis. Instituto Tecnológico de Tapachula.

Wilhere GF (2008) How-much-is-enough myth. Cons Biol 22: 514-517.

Winkler M, Huber K, Hiet P (2009) Population dynamics of epiphytic orchids in a metapopulation context. Ann Bot 104: 995-1004. 